\title{
Ooctonus vulgatus (Hymenoptera, Mymaridae), a potential biocontrol agent to reduce populations of Philaenus spumarius (Hemiptera, Aphrophoridae) the main vector of Xylella fastidiosa in Europe.
}

Xavier Mesmin ${ }^{1,2}$, Marguerite Chartois ${ }^{2}$, Guenaelle Genson ${ }^{2}$, Jean-Pierre Rossi ${ }^{2}$, Astrid Cruaud ${ }^{2}$, Jean-Yves Rasplus ${ }^{\text {Corresp. } 2}$

1 AGAP, INRAE, CIRAD, Montpellier SupAgro, Univ Montpellier, San Giuliano, France

2 CBGP, INRAE, CIRAD, IRD, Montpellier SupAgro, Univ Montpellier, Montpellier, France

Corresponding Author: Jean-Yves Rasplus

Email address: jean-yves.rasplus@inra.fr

As a vector of Xylella fastidiosa (Wells, 1987) in Europe, the meadow spittlebug Philaenus spumarius (Linnaeus, 1758) (Hemiptera, Aphrophoridae) is a species of major concern. Therefore, tools and agents to control this ubiquitous insect that develops and feeds on hundreds of plant species are wanted. We conducted a field survey of $P$. spumarius eggs in Corsica and provide a first report of Ooctonus vulgatus Haliday, 1833 (Hymenoptera, Mymaridae) as a potential biocontrol agent of $P$. spumarius in Europe. To allow species identification, we summarized the main characters distinguishing $O$. vulgatus from other European species of Ooctonus and generated COI DNA barcodes. Parasitism rates were variable in the four localities included in the survey but could reach $69 \%$ (for an average number of eggs that hatched per locality of 109). Based on the geographic occurrences of $O$. vulgatus obtained from the literature, we calibrated an ecological niche model to assess its potential distribution in the Holarctic. Obviously, several questions need to be addressed to determine whether $O$. vulgatus could become an effective biocontrol agent of $P$. spumarius in Europe. So far, O. vulgatus has been reared only from $P$. spumarius eggs, but its exact host-range should be evaluated to ensure efficiency and avoid non-target effect. The top-down impact of the parasitoid on vector populations should also be assessed on large data sets. Finally, the feasibility of mass rearing should be tested. We hope this report serves as a starting point to initiate research on this parasitoid wasp to assess whether it could contribute to reduce the spread and impact of $X$. fastidiosa in Europe. 
1 Ooctonus vulgatus (Hymenoptera, Mymaridae), a potential biocontrol agent to reduce 2 populations of Philaenus spumarius (Hemiptera, Aphrophoridae) the main vector of Xylella 3 fastidiosa in Europe.

7 Xavier Mesmin ${ }^{1,2}$, Marguerite Chartois², Guénaëlle Genson², Jean-Pierre Rossi², Astrid Cruaud² \& 8 Jean-Yves Rasplus ${ }^{2 f}$

${ }^{1}$ AGAP, INRAE, CIRAD, Montpellier SupAgro, Univ Montpellier, San Giuliano, France

$12{ }^{2}$ CBGP, INRAE, CIRAD, IRD, Montpellier SupAgro, Univ Montpellier, Montpellier, France

13 fcorresponding author: jean-yves.rasplus@inrae.fr

ABSTRACT

17 As a vector of Xylella fastidiosa (Wells, 1987) in Europe, the meadow spittlebug Philaenus 18 spumarius (Linnaeus, 1758) (Hemiptera, Aphrophoridae) is a species of major concern. Therefore,

19 tools and agents to control this ubiquitous insect that develops and feeds on hundreds of plant

20 species are wanted. We conducted a field survey of $P$. spumarius eggs in Corsica and provide a 21 first report of Ooctonus vulgatus Haliday, 1833 (Hymenoptera, Mymaridae) as a potential

22 biocontrol agent of $P$. spumarius in Europe. To allow species identification, we summarized the

23 main characters distinguishing 0 . vulgatus from other European species of Ooctonus and

24 generated COI DNA barcodes. Parasitism rates were variable in the four localities included in the

25 survey but could reach 69\% (for an average number of eggs that hatched per locality of 109).

26 Based on the geographic occurrences of 0 . vulgatus obtained from the literature, we calibrated 
27 an ecological niche model to assess its potential distribution in the Holarctic. Obviously, several

28 questions need to be addressed to determine whether O. vulgatus could become an effective

29 biocontrol agent of $P$. spumarius in Europe. So far, $O$. vulgatus has been reared only from $P$.

30 spumarius eggs, but its exact host-range should be evaluated to ensure efficiency and avoid non-

31 target effect. The top-down impact of the parasitoid on vector populations should also be

32 assessed on large data sets. Finally, the feasibility of mass rearing should be tested. We hope this

33 report serves as a starting point to initiate research on this parasitoid wasp to assess whether it

34 could contribute to reduce the spread and impact of $X$. fastidiosa in Europe. 


\section{INTRODUCTION}

38 Xylella fastidiosa (Wells, 1987) is a xylem-dwelling insect-borne bacterium that originates from

39 the Americas, infects more than 500 species of plants (EFSA, 2015) and causes a variety of scorch-

40 like diseases in many cultivated species (Almeida \& Nunney, 2015; EFSA, 2018; Sicard et al.,

41 2018). Studies on the economic impact of $X$. fastidiosa have primarily focused on the wine and

42 grape industries. Yield reduction and management costs to the California grape industry are

43 estimated at more than US\$100 million per year (Tumber, Alston \& Fuller, 2014) and a potential

44 introduction of the bacterium in Australia is estimated to cost up to AUD 7.9 billion over 50 years

45 (Hafi et al., 2017).

46 X. fastidiosa has been recently detected in Europe and is present in Italy (Saponari et al., 2013),

47 France (Denancé et al., 2017), Spain (Olmo et al., 2017), and Portugal (DGAV, 2019). Furthermore,

48 niche modelling has shown that a large part of Europe is climatically suitable for the bacterium

49 (Godefroid et al., 2018, 2019). Hence, X. fastidiosa represents a serious threat to European

50 agriculture and natural ecosystems.

51 The spread of $X$. fastidiosa depends on several interacting factors, mainly insect vectors and

52 plant communities as well as landscape, climate features and population dynamics of the

53 bacterium itself (Krugner et al., 2019). As a consequence, disease management is complex.

54 Reducing bacterium spread requires acting on a set of different biotic and abiotic factors

55 (Almeida et al., 2005) and modelling approaches may help setting up effective strategies (Fierro,

56 Liccardo \& Porcelli, 2019). Here we focus on a possible management strategy to control

57 populations of the most common vector of $X$. fastidiosa reported in Europe so far: the meadow 
58 spittlebug Philaenus spumarius (Linnaeus, 1758) (Hemiptera, Aphrophoridae) (Saponari et al.,

59 2014; Cornara et al., 2016).

60 P. spumarius is highly polyphagous (Cornara, Bosco \& Fereres, 2018), widely distributed in the

61 Palearctic from sea level to high elevation (about 2000m; e.g. Halkka, Raatikainen \& Vilbaste,

62 1975; Lees, Dent \& Gait, 1983; Drosopoulos \& Asche, 1991; Loukas \& Drosopoulos, 1992;

63 Quartau, Borges \& André, 1992; Stewart \& Lees, 1996; Drosopoulos \& Remane, 2000), and was

64 probably introduced to the New World (Whittaker, 1973). Its ability to acquire and transmit $X$.

65 fastidiosa was previously demonstrated (Severin, 1950; Saponari et al., 2014; Cornara et al., 66 2016).

67 So far, a few studies have assessed the impact of different insecticides to reduce juvenile 68 populations of $P$. spumarius in Europe (Dongiovanni et al., 2018; Dáder et al., 2019). However,

69 there is a growing awareness of the need to encourage management practices that safeguard

70 harvests, human health, biodiversity and the environment. Thus, the development of effective

71 biological control programs is desirable. Among biocontrol strategies, augmentative biological

72 control consists in enhancing the effectiveness of naturally occurring natural enemies by the

73 periodic release of specimens (Eilenberg, Hajek \& Lomer, 2001; Aubertot \& Savary, 2005).

74 Compared to classical biological control it eliminates unintended effects of the introduction of 75 new, non-native, parasitoids or predaceous arthropods (Hoy, 2008). However, as for all biological 76 control programs, augmentative biocontrol requires field investigations to identify potential 77 natural enemies of the target pest.

78 Currently, information about the natural enemies of the meadow spittlebug are scattered

79 (Cornara et al. 2018). Species of birds, frogs, arachnids, and insects (Hymenoptera, Diptera, and 
80 Coleoptera) occasionally feed on P. spumarius (Phillipson, 1960; Halkka \& Kohila, 1976; Harper \&

81 Whittaker, 1976; Henderson, Hoffman \& Jeanne, 1990; Pagliano \& Alma, 1997) but predation by

82 native natural enemies does not appear to be an important source of mortality. Studies are in

83 progress to test whether the invasive assassin bug Zelus renardii Kolenati, 1857 (Hemiptera,

84 Reduviidae) could be used to control populations of $P$. spumarius in olive orchards (Salerno et al.,

85 2017). However, mass release of this species may be risky for local biodiversity, especially for

86 beneficial arthropods (Ables, 1978). Indeed, it is considered as a generalist predator (Ables, 1978,

87 Cisneros \& Rosenheim, 1998; Weirauch, Alvarez \& Zhang, 2012, Salerno et al., 2017, but see

88 Cohen \& Tang, 1997 who suggest a strong effect of prey body size).

89 So far, only few parasitoids of $P$. spumarius have been recorded. Adults are attacked by

90 Verralia aucta (Fallen, 1817) (Diptera, Pipunculidae) in Europe with relatively high parasitism

91 rates in England: in average 31\% in females and 46\% in males over four years (Whittaker, 1969,

92 1973). Parasitism by $V$. aucta has a direct effect on $P$. spumarius population dynamics because it

93 renders the host sterile (Whittaker, 1973). However, this parasitoid does not have an immediate

94 effect on bacterium transmission because adults are only killed after 10-11 weeks of parasitism

95 (Whittaker, 1969), a period during which they are probably still able to spread the bacterium.

96 Contrastingly, an interesting feature of egg parasitoids is that they kill the host in the egg stage,

97 that is, before it can inflict damage to its host plants (Mills, 2010). In the case of $P$. spumarius, the

98 insect is killed before it acquires the bacterium from an infected host plant and becomes able to

99 transmit it. A few egg parasitoids have been recorded in the US: Ooctonus vulgatus Haliday, 1833

100 (Hymenoptera, Mymaridae) and at least two unnamed species of Centrodora (Hymenoptera,

101 Aphelinidae) (Weaver \& King, 1954). Indeed, the genus Tumidiscapus, which is cited as parasitoid 
102 of $P$. spumarius in the US (Weaver \& King, 1954), is in fact a synonym of Centrodora (Hayat, 1983).

103 However, little is known about the biology and efficacy of egg parasitoids in natura.

104 In this study, a field survey was conducted to identify major egg parasitoids of $P$. spumarius in

105 Corsica. We provide a first report of Ooctonus vulgatus in this area. We summarized the main

106 characters separating 0 . vulgatus from other Palearctic species to facilitate identification and

107 generate COI DNA barcodes to accurately identify the species. Finally, we reviewed the literature

108 and gathered all available occurrence data (i.e. geographical coordinates) of previously detected

109 populations of $O$. vulgatus. This allowed us to calibrate an ecological niche model linking different

110 climate descriptors to species occurrence data and estimate the potential distribution of the

111 parasitoid in the Holarctic region for comparison with the distribution of $P$. spumarius.

112

\section{MATERIALS AND METHODS}

115 Sampling and calculation of parasitism rate

116 Five to ten handfuls of about eight top branches of Cistus monspeliensis L. 1753 (cut at $50 \mathrm{~cm}$

117 below the end of the branch) were sampled in four localities (Figure 1). These localities were part

118 of a larger field survey of population dynamics of $P$. spumarius in Corsica. We targeted $C$.

119 monspeliensis to maximize our chances to find eggs of $P$. spumarius. Indeed, we demonstrated

120 in a previous study that, in Corsica, adults of $P$. spumarius seemed to be mainly associated with

121 this species (Cruaud et al., 2018). Sampling was performed between the $12^{\text {th }}$ and the $15^{\text {th }}$ of

122 February 2019. The back of each leaf (about 900 leaves per handful of branches) was inspected

123 in the laboratory for whitish clusters, which were retained and inspected under a binocular 
124 microscope to confirm the presence of eggs of P. spumarius (Appendix S1; 109, 148, 167, 187

125 eggs obtained per site, hence a total of 611 eggs monitored). The morphological identification of

126 P. spumarius eggs and first stage nymphs was performed using the descriptions of Weaver and

127 King (1954) (Appendix S1). The pieces of leaf containing the eggs were placed on filter papers in

128 unaerated Petri dishes (i.e. without spur) at room temperature $\left(20.2 \pm 1.5^{\circ} \mathrm{C}\right)$, with natural light.

129 Filter papers were kept moist by adding drops of water when necessary. Hatching was monitored

130 every morning from the $18^{\text {th }}$ of February to the $15^{\text {th }}$ of March 2019 . Emerging nymphs and

131 parasitoids were killed and stored in $70 \%$ Ethanol at $4^{\circ} \mathrm{C}$. Parasitism rates were computed in each

132 locality with the following formula: Parasitism rate =

$133 \frac{\text { Number of parasitized eggs }}{\text { Number of parasitized eggs }+ \text { Number of unparasitized eggs }}$ (Costello \& Altieri, 1995).

135 Morphological identification of the parasitoids

136 Identification to species was performed using the Ooctonus keys by Triapitsyn (2010) and Huber

137 (2012). Specimens were desiccated using HMDS (Heraty \& Hawks, 1998) and glued on grey cards.

138 Imaging was performed with a Keyence digital microscope (VHX-5000 Camera color CMOS and

139 the $\mathrm{VH}-\mathrm{Z100UT}$ lens). Images were then edited in Adobe Photoshop $\mathrm{CS}^{\odot}{ }^{\odot}$ software.

140

141 Molecular identification of the parasitoids

142 Six individuals were used for molecular identification. Three of them were handled individually

143 (sample codes $=$ XMES00042_0101, XMES00077_0101, XMES00091_0101) and the remaining

144 three were pooled to increase DNA yield (sample code = XMES00041_0189). Total genomic DNA

145 was isolated using the Qiagen DNeasy Blood \& Tissue kit without destruction of the specimens. 
146 We followed manufacturer's protocol with the following modifications. Samples (whole insects,

147 without dissection or crushing) were incubated overnight in an Eppendorf thermomixer

148 (temperature $=56^{\circ} \mathrm{C}$, mixing frequency $=300 \mathrm{rpm}$ ). To increase DNA yield, two successive

149 elutions ( $50 \mu \mathrm{L}$ each) were performed with heated buffer $\mathrm{AE}\left(56^{\circ} \mathrm{C}\right)$ and an incubation step of 15

150 minutes followed by centrifugation (6000g for 1 minute at room temperature; see Cruaud et al.

1512019 for a detailed description of the protocol). Eppendorf microtubes LoBind 1.5ml were used

152 for elution and to store DNA at minus $20^{\circ} \mathrm{C}$ until PCR amplification. Vouchers were deposited at

153 Centre de Biologie pour la Gestion des Populations (CBGP), Montferrier-sur-Lez, France. The

154 mitochondrial Cytochrome c oxidase I standard barcode fragment (COI) was amplified with a

155 cocktail of M13-tailed primers as detailed in Germain et al. (2013). Unpurified PCR products were

156 sent to Eurofins MWG Operon (Ebersberg, Germany) for sequencing using the M13F and M13R

157 primers (Germain et al., 2013; Ivanova et al., 2007). Both strands for each overlapping fragment

158 were assembled in Geneious v11.1.4 (https://www.geneious.com). Geneious was also used to

159 translate consensus sequences to amino acids to detect premature codon stops. All COI

160 sequences available on BOLD (Ratnasingham \& Hebert, 2007) for Ooctonus species were

161 downloaded (last access July 12,2019) and aligned with the newly generated sequences using

162 MAFFT v7.245 (Katoh \& Standley, 2013). A maximum likelihood tree was inferred with raxmlHPC-

163 PTHREADS-AVX version 8.2.4 (Stamatakis, 2014). A rapid bootstrap search (100 replicates)

164 followed by a thorough ML search (-m GTRGAMMA) was conducted. Tree visualization and

165 annotation was performed with TreeGraph 2.13 (Stöver \& Müller, 2010).

166

167 Species distribution modelling framework

Peer] reviewing PDF | (2019:09:40940:2:0:NEW 10 Jan 2020) 
168 Occurrences of $O$. vulgatus were retrieved from the literature and the GBIF database (GBIF.org

169 2019) (Tables S1\&S2). Two hundred and five occurrences were obtained from the literature

170 (Table S1), eight of which were not included in the analysis as no geographic coordinates were

171 available. Forty occurrences were obtained from GBIF (last access: 22 August 2019; Table S2), but

172 were all discarded due to dubious identification or lack of information on sample origin.

173 Therefore, no occurrence obtained from GBIF could be included in the analysis.

174

175 We fitted a correlative model linking different climate descriptors to species occurrences. The

176 Maxent algorithm was chosen to conduct analyses because it does not require absence data (i.e.

177 locations in which we can presume that a species is truly absent) (Phillips et al., 2006). We

178 summarized below the main step of our analysis and details are provided in Appendix S2. The

179 mean temperature and precipitation of the wettest, driest, warmest, and coldest quarters as well

180 as precipitation seasonality were extracted from the Worldclim 2.0 database (Fick \& Hijmans,

181 2017) and used as bioclimatic descriptors (Hijmans et al., 2005). In absence of formal knowledge

182 about climatic factors constraining 0 . vulgatus distribution, we constituted three sets of

183 bioclimatic variables and performed modelling with each of them (Qiao, Soberón \& Peterson,

184 2015; Godefroid et al., 2019). The first set (CLIM1) comprised the mean temperature of the

185 wettest, driest, warmest, and coldest quarters to reflect the impact of temperature constraints

186 on distribution. To highlight the precipitation constraint, we added the precipitation seasonality

187 to CLIM1 and constituted the second set (CLIM2). Finally, we built a third set (CLIM3) by

188 assembling CLIM1 and the precipitation of the wettest, driest, warmest, and coldest quarters to

189 fully account for both extreme temperatures and precipitations in the species distribution models

Peer] reviewing PDF | (2019:09:40940:2:0:NEW 10 Jan 2020) 
190 (SDMs). The Maxent algorithm requires a set of locations where the species has been found

191 (here, a random $70 \%$ of the available occurrences, the other $30 \%$ being used for model

192 validation) and a set of locations where no information about the presence of the species are

193 available (referred to as background points). A total of 10,000 background points were randomly

194 generated in North America and Europe). To render complex response to environmental

195 constraints while reducing model overfitting we first fitted 48 Maxent models using six

196 regularization multiplier (RM) combinations ( $\mathrm{L}, \mathrm{LQ}, \mathrm{H}, \mathrm{LQH}, \mathrm{LQHP}, \mathrm{LQHPT}$ with L=linear,

$197 \mathrm{Q}=$ quadratic, $\mathrm{H}=$ hinge, $\mathrm{P}=$ product and $\mathrm{T}$ =threshold) and feature class $(\mathrm{FC}$ ) values (eight values

198 ranging from 0.5 to 4 with increments of 0.5) (Radosavljevic \& Anderson, 2014). Optimal FC and

199 RM combinations were determined for each of the three bioclimatic datasets (CLIM1 - CLIM3)

200 using the R language ( $R$ core team 2019) and the package ENMeval (Muscarella et al., 2014).

201 Optimal parameters were then used to fit a set of 10 replicate Maxent models using $70 \%$ of the

202 dataset. The performance of each model was evaluated using the remaining $30 \%$ of occurrences

203 using the area under the receiver-operator curve (AUC, Fielding \& Bell, 1997) and the true skill

204 statistics (TSS, Allouche, Tsoar \& Kadmon, 2006). Models with AUC $<0.8$ were excluded from

205 further analyses (Vicente et al., 2013). Habitat suitability maps (logistic output ranging from 0 to

206 1) were transformed into binary projections using the threshold that optimized the TSS statistics

207 on the testing data (Guisan, Thuiller \& Zimmermann, 2017). Maxent replicate models were fitted

208 and evaluated using the R package biomod2 (Thuiller et al., 2009).

209 Two different outputs were generated using the set of model prediction. i) Binary predictions

210 were averaged to produce the committee (consensus) averaging (Araújo \& New, 2007; Marmion

211 et al., 2009) showing the likelihood of the presence of $O$. vulgatus. This consensus model ranges 
212 from 0 (all the models predict absence) to $100 \%$ (all the models predict presence) and ii) the

213 median of the logistic outputs (Guisan, Thuiller \& Zimmermann, 2017) of the models that depicts

214 the climate suitability across the different models.

215

216 RESULTS

217

218 Parasitism rates.

219 Out of the 611 eggs monitored, 437 (i.e. $71.5 \%$ ) hatched. 277 (63.4\%) gave rise to P. spumarius 220 nymphs and parasitoids emerged from 160 eggs (36.6\%). All parasitoids were identified as $O$.

221 vulgatus (Figure 2). No parasitoid emerged from eggs collected in one of the four localities. We 222 observed parasitism rates of 20.5, 48.9 and $69.0 \%$ in the three other localities (Figure 1).

223

224 Guidelines for the identification of $O$. vulgatus.

225 To help identification, we list below the main features that differentiate $O$. vulgatus from its

226 closest relatives. The genus Ooctonus has been recently revised in the Palearctic and Nearctic

227 regions respectively by Triapitsyn (2010) and Huber (2012). Ooctonus can be distinguished from

228 other genera of Mymaridae by the following set of characters: tarsi 5-segmented, propodeum

229 with diamond-shaped pattern of carinae (Figure 2F), fore wing venation about one-third the wing

230 length (Figure 2C), with short marginal and stigmal vein, parastigma with hypochaeta next to

231 proximal macrochaeta (Huber, 2012). In the Holarctic region, O. vulgatus can be distinguished

232 from other species of Ooctonus by the following unique combination of features (Figure 2): vertex

233 without stemmaticum; mesoscutum without median groove; posterior part of scutellum and 
234 frenum smooth with weak sculpture laterally; metanotum and propodeum without reticulate

235 sculpture; propodeum without median carina, but with a pentagonal areole formed by 236 dorsolateral carinae; short petiole, $0.9-1.2 x$ as long as metacoxa; forewing at least slightly

237 truncate apically; females funicle with multiporous placoid sensilla (mps) on F7 and F8 only, F5

238 and F6 without mps; single row of six bullae inside the female clava; ovipositor at most $1.4 \times$ as

239 long as metatibia and only slightly exerted beyond apex of gaster.

\section{Molecular identification of the parasitoid.}

242 Barcode sequences were successfully generated from all samples. All sequences were identical.

243 Phylogenetic analysis confirmed that the most likely identification was O. vulgatus (Figure S1).

245 Species distribution modelling.

246 A total of 200 occurrences (197 obtained from the literature plus the three localities where we

247 sampled O. vulgatus) (Figure 3A) were used to model the distribution of $O$. vulgatus in Europe.

248 The optimal Maxent parameters were $\mathrm{RM}=4$ and $\mathrm{FC}=$ hinge; $\mathrm{RM}=4$ and $\mathrm{FC}=$ hinge and $\mathrm{RM}=2.5$ and

249 FC=hinge for CLIM1, CLIM2, and CLIM3, respectively. With the exception of one model of CLIM2,

250 all models based on these optimal values yielded AUC values $>0.8$, which indicated that the

251 different bioclimatic data subsets performed well. The consensus model was therefore computed

252 from a set of 29 estimates of climate suitability.

253 Figure 3B shows the median of the climate suitability values for the 29 models considered. Figure

$2543 \mathrm{C}$ depicts the proportion of the 29 models indicating that the climate is suitable for $O$. vulgatus.

255 Both Figure $3 \mathrm{~B}$ and $3 \mathrm{C}$ show that the climate is favorable in very large areas covering most of 
256 Western Europe and around the Black Sea. These areas are overlapping with the geographical

257 range of $P$. spumarius (Cruaud et al. 2018).

258

259

DISCUSSION

260

Ooctonus Haliday, 1833 is a medium-sized genus of Mymaridae containing 37 described

261 species that occur in all zoogeographical regions of the world (Holt et al., 2013) excepted

262 Australasia (Noyes, 2019). O. vulgatus has been reared from the eggs of $P$. spumarius and studied

263 only once in North America (Weaver \& King, 1954). This species is thus poorly known as

264 confirmed by the limited barcoding record. Indeed, only four barcodes are available in BOLD (two

265 from Virginia United States, one from Ontario Canada, and one from British Columbia Canada).

266 As a likely component of aerial plankton, O. vulgatus is expected to be a widespread species

267 distributed in the Holarctic region (ranging from Ireland to the Sakhalin peninsula and from

268 eastern to western coasts of North America, as south as California (Huber, 2012)). The species

269 has been also reported from China (Bai, Jin \& Li, 2015) but authors' illustration casts some doubts

270 about specimen identification. There are only a few unquestionable occurrences in the literature

271 for this species $(n=197)$. Here, we provide a first report of 0 . vulgatus in Corsica and assess, for

272 the first time in Europe, its biology as parasitoid of $P$. spumarius. We also confirm its potential

273 large distribution throughout Europe with modelling approaches. More importantly we show

274 that $O$. vulgatus potential distribution in Europe (Figure 3) overlaps that of its host $P$. spumarius

275 (Cruaud et al., 2018), which is not surprising from a biological point of view but is an interesting

276 result in the framework of biological control. This study is preliminary and predictions, especially

277 because they are based on a limited number of occurrences, are indicative only. This study is a

Peer] reviewing PDF | (2019:09:40940:2:0:NEW 10 Jan 2020) 
278 starting point to encourage investigations in other parts of Europe. Sampling efforts should more

279 specifically target areas predicted as suitable for $P$. spumarius but non-suitable for $O$. vulgatus

280 such as eastern areas of Europe.

281 When studied in North America, observed parasitism rates did not exceed $10 \%$ of the

282 sampled eggs of $P$. spumarius (Weaver \& King, 1954). Here, we obtained parasitism rates of up

283 to $69 \%$, but absence of parasitism in one sampled site. While we acknowledge sampling four

284 sites is not enough to have a representative view of $P$. spumarius egg parasitism in Corsica, our

285 results show that parasitism rate can be high though very variable. Further surveys are obviously

286 necessary to better assess the spatial and temporal variability of parasitism rate and understand

287 what is(are) the cause(s) of such variations in Corsica and throughout Europe. Identifying such

288 drivers could open new avenues for conservation biological control against $P$. spumarius, through

289 the implementation of environments favorable to 0 . vulgatus in the vicinity of crops susceptible

290 to X. fastidiosa.

291 The use of mymarids in biological control program has a long history. The most notable

292 instance being the use of Anaphes nitens (Girault, 1928) in several countries to successfully

293 control the eucalyptus weevil, Gonipterus scutellatus Gyllenhal, 1833 (Coleoptera,

294 Curculionidae), which feeds and reproduces on Eucalyptus trees (Doull, 1955). More recently,

295 Cleruchoides noackae Lin and Huber, 2007 has been used in South America to control an invasive

296 sap-feeding pest of Eucalyptus, Thaumastocoris peregrinus Carpintero and Dellapé, 2006

297 (Hemiptera, Thaumastocoridae) (Martínez, González \& Dicke, 2018). Mymarid species were used

298 to control leafhopper vectors of plant pathogens (Hemiptera, Cicadellidae). Anagrus armatus

299 (Ashmead, 1887) regulated Edwardsiana froggatti (Baker, 1925) (Hemiptera, Cicadellidae), a pest

Peer] reviewing PDF | (2019:09:40940:2:0:NEW 10 Jan 2020) 
300 of apple in New Zealand, with parasitism rates of the eggs reaching $80 \%$ (Dumbleton, 1937). More

301 recently, Cosmocomoidea species were used to target Homalodisca vitripennis (Germar, 1821)

302 (Hemiptera, Cicadellidae) a vector of $X$. fastidiosa in California (Irvin \& Hoddle, 2010). In all these

303 cases, mymarids helped regulate pest population growth.

$304 \quad$ However, before any attempts to regulate populations of $P$. spumarius are made, we need

305 to enrich our knowledge on $O$. vulgatus. In particular, the degree of specificity of the $P$. spumarius

$306-0$. vulgatus interaction needs to be determined to avoid non-target effect of augmentative

307 biocontrol (Van Driesche \& Hoddle, 2016). We also need to evaluate our ability to consistently

308 rear 0 . vulgatus in controlled conditions, one of the key obstacles to the use of mymarids in

309 biological control programs (but see Martínez, González \& Dicke, 2018). Finally, parasitoids can

310 have complex effects on vector-borne disease by either increasing (Jeger et al., 2011) or

311 decreasing (Martini, Pelz-Stelinski \& Stelinski, 2014) pathogen spread. Further research is still

312 needed to better understand the impact of such tri-trophic interactions on plant disease

313 dynamics. While $O$. vulgatus does not directly impact transmission capacity of $P$. spumarius, by

314 killing its host at an early stage of development, it reduces the number of vectors that may

315 acquire the bacterium from an infected host-plant and become able to transmit it.

316 Again, we consider this study as a starting point to encourage research on this parasitoid

317 wasp to assess whether it could contribute to reduce the spread and impact of $X$. fastidiosa in

318 Europe. Increasing egg parasitism of $P$. spumarius in the fall might significantly reduce population

319 size in the next year and possibly the transmission of the bacterium, without resorting to 320 chemical treatments. 


\section{REFERENCES}

327

328

Ables JR. 1978. Feeding Behavior of an Assassin Bug, Zelus renardii. Annals of the Entomological Society of America 71:476-478. DOI: 10.1093/aesa/71.4.476.

Allouche O, Tsoar A, and Kadmon R. 2006. Assessing the accuracy of species distribution models: prevalence, kappa and the true skill statistic (TSS). Journal of applied ecology 43:1223-1232.

Almeida RP, Blua MJ, Lopes JRS, and Purcell AH. 2005. Vector transmission of Xylella fastidiosa: Applying fundamental knowledge to generate disease management strategies. Annals of the Entomological Society of America 98:775-786.

Almeida RP, and Nunney L. 2015. How do plant diseases caused by Xylella fastidiosa emerge? Plant Disease 99:1457-1467.

Araújo MB, and New M. 2007. Ensemble forecasting of species distributions. Trends in ecology \& evolution 22:42-47.

Aubertot J-N, and Savary S. 2005. Chapitre 4 : Stratégies de protection des cultures, p. 104. In . Expertise Scientifique Collective "Pesticides, Agriculture et Environnement" Available from : http://institutinrafr/Missions/Eclairer-les-decisions/Expertises/Toutes-lesactualites/Pesticides-agriculture-et-environnement.

Bai H-F, Jin X-X, and Li C-D. 2015. A taxonomic study of Ooctonus (Hymenoptera, Mymaridae) from Heilongjiang, China. ZooKeys 479:25-36.

Cisneros JJ, Rosenheim JA. 1998. Changes in the Foraging Behavior, Within-Plant Vertical Distribution, and Microhabitat Selection of a Generalist Insect Predator: an Age Analysis. Environmental Entomology 27:949-957. DOI: 10.1093/ee/27.4.949. 
348 Cohen AC, Tang R. 1997. Relative Prey Weight Influences Handling Time and Biomass Extraction

349 in Sinea confusa and Zelus renardii (Heteroptera: Reduviidae). Environmental

$350 \quad$ Entomology 26:559-565. DOI: 10.1093/ee/26.3.559.

351 Cornara D, Bosco D, and Fereres A. 2018. Philaenus spumarius: when an old acquaintance

352 becomes a new threat to European agriculture. Journal of Pest Science 91:957-972.

$353 \quad 10.1007 /$ s10340-018-0966-0

354 Cornara D, Cavalieri V, Dongiovanni C, Altamura G, Palmisano F, Bosco D, Porcelli F, Almeida

355 RPP, and Saponari M. 2016. Transmission of Xylella fastidiosa by naturally infected Philaenus spumarius (Hemiptera, Aphrophoridae) to different host plants. Journal of Applied Entomology 141:80-87.

Costello MJ, Altieri MA. 1995. Abundance, growth rate and parasitism of Brevicoryne brassicae and Myzus persicae (Homoptera: Aphididae) on broccoli grown in living mulches. Agriculture, Ecosystems \& Environment 52:187-196. DOI: 10.1016/0167-8809(94)00535-

Cruaud A, Gonzalez A-A, Godefroid M, Nidelet S, Streito J-C, Thuillier J-M, Rossi J-P, Santoni S, and Rasplus J-Y. 2018. Using insects to detect, monitor and predict the distribution of Xylella fastidiosa: a case study in Corsica. Scientific Reports 8:15628. 10.1038/s41598018-33957-z

Cruaud A, Nidelet S, Arnal P, Weber A, Fusu L, Gumovsky A, Huber J, Polaszek A, and Rasplus JY. 2019. Optimised DNA extraction and library preparation for small arthropods: application to target enrichment in chalcid wasps used for biocontrol. Molecular Ecology Resources. https://doi.org/10.1111/1755-0998.13006

Dader B, Vinuela E, Moreno A, Plaza M, Garzo E, Del Estal P, and Fereres A. 2019. Sulfoxaflor

Denancé N, Legendre B, Briand M, Olivier V, de Boisseson F, Poliakoff F, and Jacques M-A. 2017. Several subspecies and sequence types are associated with the emergence of Xylella fastidiosa in natural settings in France. Plant Pathology 66:1054-1064. 
377 DGAV. 2019. Oficio Circular n. 2/2019. Primeira deteção de Xylella fastidiosa em Portugal.

378 (available from https://wwwconfagript/content/uploads/2019/01/Oficio-circular-2_2019_-

$379 \quad$ Xfastidosapdf).

380 Dongiovanni C, Di Carolo M, Fumarola G, Tauro D, Altamura G, and Cavalieri V. 2018. Evaluation

381 of insecticides for the control of juveniles of Philaenus spumarius L., 2015-2017.

$382 \quad$ Arthropod Management Tests 43:tsy073.

383 Doull KM. 1955. The biological control of noxious plants and insects. Rural Education Bulletin, $384 \quad$ Lincoln College, New Zealand 10:98-128.

385 Drosopoulos S, and Asche M. 1991. Biosystematic studies on the spittlebug genus Philaenus

386 with the description of new species. Zoological Journal of the Linnean Society 101:169-

$387 \quad 177$.

388 Drosopoulos S, and Remane R. 2000. Biogeographic studies on the spittlebug Philaenus signatus Melichar, 1896 species group (Hemiptera: Aphrophoridae) with the description of two new allopatric species. Ann Soc Entomol Fr 36:269-277

Dumbleton L. 1937. Apple leaf-hopper investigations. New Zealand Journal of Science and Technology 18:866- 877.

EFSA. 2015. Scientific Opinion on the risk to plant health posed by Xylella fastidiosa in the EU territory, with the identification and evaluation of risk reduction, EFSA Journal 2015;13(1):3989.

EFSA. 2018. Scientific report on the update of the Xylella spp. host plant database. EFSA Journal 16:5408. https://doi.org/10.2903/j.efsa.2018.5408

Eilenberg J, Hajek A, and Lomer C. 2001. Suggestions for unifying the terminology in biological control. BioControl 46:387-400.

Fick SE, and Hijmans RJ. 2017. WorldClim 2: new 1-km spatial resolution climate surfaces for global land areas. International journal of climatology 37:4302-4315.

Fielding $\mathrm{AH}$, and Bell JF. 1997. A review of methods for the assessment of prediction errors in conservation presence/absence models. Environ Conserv 24:38-49.

Fierro A, Liccardo A, and Porcelli F. 2019. A lattice model to manage the vector and the infection of the Xylella fastidiosa on olive trees. Scientific Reports 9:8723. 
406 GBIF.org. 2019. GBIF Home Page. Available from: https://www.gbif.org

407 Germain JF, Chatot C, Meusnier I, Artige E, Rasplus J-Y, and Cruaud A. 2013. Molecular

408 identification of Epitrix potato flea beetles (Coleoptera: Chrysomelidae) in Europe and

$409 \quad$ North America. Bulletin of Entomological Research 103:354-362.

410 Godefroid M, Cruaud A, Streito J-C, Rasplus J-Y, and Rossi J-P. 2018. Climate change and the

411 potential distribution of Xylella fastidiosa in Europe. bioRxiv.

412 https://doi.org/10.1101/289876

413 Godefroid M, Cruaud A, Streito J-C, Rasplus J-Y, and Rossi J-P. 2019. Xylella fastidiosa: climate

414 suitability of European continent. Scientific Reports 9:8844. 10.1038/s41598-019-45365-

$415 \quad \mathrm{y}$

416 Guisan A, Thuiller W, and Zimmermann NE. 2017. Habitat suitability and distribution models:

$417 \quad$ with applications in R: Cambridge University Press.

418 Hafi A, Randall L, Arthur T, Addai D, Tennant P, and Gomboso J. 2017. Economic impacts of

419 Xylella fastidiosa on the Australian wine grape and wine-making industries. Department 420 of Agriculture and Water Resources ABARES.

421 Halkka O, Raatikainen M, Vilbaste J. 1975. Clines in the colour polymorphism of Philaenus 422 spumarius in Eastern Central Europe. Heredity 35:303-309. DOI: 10.1038/hdy.1975.101.

423 Halkka O, and Kohila T. 1976. Persistence of visual polymorphism, despite a low rate of 424

425 predation, in Philaenus spumarius (L.)(Homoptera, Aphrophoridae). Annales Zoologici Fennici 13:185-188.

Harper G, and Whittaker JB. 1976. The role of natural enemies in the colour polymorphism of Philaenus spumarius (L.). Journal of Animal Ecology 45:91-104.

Hayat M. 1983. The genera of Aphelinidae of the world. Systematic Entomology 8:63-102.

Henderson G, Hoffman GD, and Jeanne RL. 1990. Predation on cercopids and material use of the spittle in aphid-tent construction by prairie ants. Psyche: A Journal of Entomology 97:43-53.

432

Heraty JM, and Hawks D. 1998. Hexamethyldisilazane - A chemical alternative for drying insects. Entomological News, 109:369-374. 
434 Hijmans RJ, Cameron SE, Parra JL, Jones PG, and Jarvis A. 2005. Very high resolution

435

436

437

438

439

440

441

442

443

444

445

446

447

448

449

450

451

452

453

454

455

456

457

458

459

460

461 interpolated climate surfaces for global land areas. International Journal of Climatology: A Journal of the Royal Meteorological Society 25:1965-1978.

Holt BG, Lessard JP, Borregaard MK, Fritz SA, Araújo MB, Dimitrov D, Fabre PH, Graham GH, Graves GR, Jønsson KA, Nogués-Bravo D, Wang Z, Whittaker RJ, Fjeldså J and Rahbek C. 2013. An update of Wallace's zoogeographic regions of the world. Science 339(6115): 74-78.

Hoy MA. 2008. Augmentative biological control. In: Capinera JL, ed. Encyclopedia of Entomology: Springer, Dordrecht.

Huber JT. 2012. Revision of the genus Ooctonus (Hymenoptera: Mymaridae). Journal of the entomological Society of Ontario 143:15-105.

Irvin NA, and Hoddle MS. 2010. Comparative assessments of Gonatocerus ashmeadi and the 'new association' parasitoid Gonatocerus tuberculifemur (Hymenoptera: Mymaridae) as biological control agents of Homalodisca vitripennis (Hemiptera: Cicadellidae). Biological Control 55:186-196.

Ivanova NV, Zemlak TS, Hanner RH, and Hebert PDN. 2007. Universal primer cocktails for fish DNA barcoding. Molecular Ecology Notes 7:544-548.

Jeger MJ, Chen Z, Powell G, Hodge S, and van den Bosch F. 2011. Interactions in a host plantvirus-vector-parasitoid system: Modelling the consequences for virus transmission and disease dynamics. Virus Research 159:183-193.

Katoh K, and Standley DM. 2013. MAFFT multiple sequence alignment software version 7: improvements in performance and usability. Molecular Biology and Evolution 30:772780.

Krugner R, Sisterson MS, Backus EA, Burbank LP, and Redak RA. 2019. Sharpshooters: a review of what moves Xylella fastidiosa. Austral Entomology 58:248-267.

Loukas M. \& Drosopoulos S. (1992) Population genetics of the spittlebug genus Philaenus (Homoptera: Cercopidae) in Greece. Biological Journal of the Linnean Society, 46, 403413. 
462 Lees DR, Dent CS, Gait PL. 1983. Geographic variation in the colour/ pattern polymorphism of 463 British Philaenus spumarius (L) (Homoptera: Aphrophoridae) populations. Biological Journal of the Linnean Society 19:99-114. DOI: 10.1111/j.1095-8312.1983.tb00779.x.

465

466

467

468

469

470

471

472

473

474

475

476

477

478

479

480

481

482

483

484

485

486

487

488

489

490

Marmion M, Parviainen M, Luoto M, Heikkinen RK, and Thuiller W. 2009. Evaluation of consensus methods in predictive species distribution modelling. Diversity and Distributions 15:59-69.

Martinez G, González A, and Dicke M. 2018. Rearing and releasing the egg parasitoid Cleruchoides noackae, a biological control agent for the Eucalyptus bronze bug. Biological Control 123:97-104.

Martini X, Pelz-Stelinski KS, and Stelinski L. 2014. Plant pathogen-induced volatiles attract parasitoids to increase parasitism of an insect vector. Frontiers in Ecology and Evolution doi.org/10.3389/fevo.2014.00008

Mills N. 2010. Egg parasitoids in biological control and integrated pest management. In: Consoli FL, Parra JRP, and Zucchi RA, eds. Egg parasitoids in agroecosystems with emphasis on Trichogramma: Springer, Dordrecht.

Muscarella R, Galante PJ, Soley-Guardia M, Boria RA, Kass JM, Uriarte M, Anderson RP, and McPherson J. 2014. ENMeval: An R package for conducting spatially independent evaluations and estimating optimal model complexity forMaxentecological niche models. Methods in ecology and evolution 5:1198-1205. 10.1111/2041-210x.12261

Noyes JS. 2019. Universal Chalcidoidea Database. Natural History Museum, London. Available from: http://www.nhm.ac.uk/jdsml/researchcuration/projects/chalcidoids/indexValidName.dsml (accessed 1 June 2019).

Olmo D, Nieto A, Adrover F, Urbano A, Beidas O, Juan A, Marco-Noales E, López MM, Navarro I, Monterde A, Montes-Borrego M, Navas-Cortés JA, and Landa BB. 2017. First detection of Xylella fastidiosa infecting cherry (Prunus avium) and Polygala myrtifolia plants, in Mallorca Island, Spain. Plant Disease 101:1820-1820.

Pagliano G, and Alma A. 1997. Ricerche etologiche su Gorytini e Alyssonini (Hymenoptera Sphecidae) parassitoidi di Auchenorryncha (Rhynchota Homoptera). Rivista Piemontese di Storia Naturale 18:173-181. 
491 Phillips SJ, Anderson RP, and Schapire RE. 2006. Maximum entropy modeling of species

492 geographic distributions. Ecological modelling 190:231-259.

493 Phillipson J. 1960. A contribution to the feeding biology of Mitopus morio (F) (Phalangida).

$494 \quad$ Journal of Animal Ecology 29:35-43.

495 Qiao H, Soberón J, and Peterson AT. 2015. No silver bullets in correlative ecological niche

496 modelling: insights from testing among many potential algorithms for niche estimation.

$497 \quad$ Methods in ecology and evolution 6:1126-1136.

498 Quartau JA, Borges PAV, André G. 1992. Philaenus spumarius (Linnaeus, 1758) new to the Azores (Homoptera, Auchenorrhyncha, Cercopidae). Boletim da Sociedade Portuguesa de Entomologia 1:129-136.

R core team. 2019. $R$ : a language and environment for statistical computing. Vienna, Austria: $R$ foundation for statistical computing.

Radosavljevic A, Anderson RP. 2014. Making better Maxent models of species distributions: complexity, overfitting and evaluation. Journal of Biogeography 41:629-643. DOI: 10.1111/jbi.12227.

Ratnasingham S, and Hebert PDN. 2007. BOLD: The Barcode of Life Data System (www.barcodinglife.org). Molecular Ecology Notes 7:355-364.

Salerno M, Russo V, Sefa V, Lamaj F, Basher N, Verrastro V, and Porcelli F. 2017. Zelus renardii an assassin bug candidate for Philaenus spumarius biocontrol. European conference on Xylella Finding answer to a global problem 13-15 Nov. Palma de Mallorca. p 22-23.

Saponari M, Boscia D, Nigro F, and Martelli GP. 2013. Identification of DNA sequences related to Xylella fastidiosa in oleander, almond and olive trees exhibiting leaf scorch symptoms

514 Saponari M, Loconsole G, Cornara D, Yokomi RK, De Stradis A, Boscia D, Bosco D, Martelli GP, Krugner R, and Porticelli F. 2014. Infectivity and transmission of Xylella fastidiosa by Philaenus spumarius (Hemiptera: Aphrophoridae) in Apulia, Italy. Journal of Economic

518 Severin, H.H.P. 1950. Spittle-insect vectors of Pierce's disease virus. Hilgardia 19: 357-382 
519 Sicard A, Zeilinger AR, Vanhove M, Schartel TE, Beal DJ, Daugherty MP, and Almeida RPP. 2018. Xylella fastidiosa: insights into an emerging plant pathogen. Annual Review of Phytopathology 56:1-22.

522

523

524

525

526

527

528

529

530

531

532

533

534

535

536

537

538

539

540

541

542

543

544

545

546

547

Stamatakis A. 2014. RAxML version 8: a tool for phylogenetic analysis and post-analysis of large phylogenies. Bioinformatics 30:1312-1313. 10.1093/bioinformatics/btu033

Stewart AJA, Lees DR. 1996. The colour/pattern polymorphism of Philaenus spumarius (L.) (Homoptera: Cercopidae) in England and Wales. Philosophical Transactions of the Royal Society of London. Series B: Biological Sciences 351:69-89. DOI: 10.1098/rstb.1996.0005.

Stöver BC, and Müller KF. 2010. TreeGraph 2: Combining and visualizing evidence from different phylogenetic analyses. BMC Bioinformatics 11:7.

Thuiller W, Lafourcade B, Engler R, and Araújo MB. 2009. BIOMOD-a platform for ensemble forecasting of species distributions. Ecography 32:369-373.

Triapitsyn SV. 2010. Revision of the Palaearctic species and review of the Oriental species of Ooctonus (Hymenoptera: Mymaridae), with notes on extralimital taxa. Zootaxa 2381:174.

Tumber KP, Alston JM, and Fuller KB. 2014. Pierce’s disease costs California \$104 million per year. California Agriculture 68:20-29.

Van Driesche R, and Hoddle MS. 2016. Non-target effects of insect biocontrol agents and trends in host specificity since 1985. CAB Reviews 11:1-66.

Vicente JR, Fernandes RF, Randin CF, Broennimann O, Gonçalves J, Marcos B, Pôças I, Alves P, Guisan A, and Honrado JP. 2013. Will climate change drive alien invasive plants into areas of high protection value? An improved model-based regional assessment to prioritise the management of invasions. Journal of environmental management 131:185-195.

Weaver CR, and King DR. 1954. Meadow spittlebug. Research bulletin of the Ohio Agricultural Experiment Station 741:1-100.

Weirauch C, Alvarez C, and Zhang G. 2012. Zelus renardii and Z. tetracanthus (Hemiptera: Reduviidae): Biological attributes and the potential for dispersal in two assassin bug species. Florida Entomologist 95:641-649. 
548 Whittaker JB. 1969. The biology of Pipunculidae (Diptera) parasitising some British Cercopidae 549 (Homoptera). Physiological Entomology 44:17-24.

550 Whittaker JB. 1973. Density regulation in a population of Philaenus spumarius (L.) (Homoptera: 551 Cercopidae). Journal of Animal Ecology 42:163-172.

552

553 FIGURE CAPTIONS

554

555 Figure 1. Parasitism rate of Philaenus spumarius eggs in the four sites sampled in Corsica.

556 Size of the pie chart is proportional to the total number of eggs that hatched from each locality

557 (n). Slices indicate the relative proportion of $O$. vulgatus (dark grey) and nymphs of $P$. spumarius 558 (light grey) that emerged from the pool of eggs. GPS coordinates of sampling localities: 559 $42.984205^{\circ} \mathrm{N}, \quad 9.395287^{\circ} \mathrm{E} \quad\left(\right.$ Ersa); $42.338849^{\circ} \mathrm{N}, \quad 9.180636^{\circ} \mathrm{E} \quad$ (Tralonca); $42.274756^{\circ} \mathrm{N}$, $9.487185^{\circ} \mathrm{E}$ (Canale-di-Verde); $41.931726^{\circ} \mathrm{N}, 9.343731^{\circ} \mathrm{E}$ (Ventiseri). The map was built with the R package maps, using data from UNESCO (1987) through UNEP/GRID-Geneva.

562

563 Figure 2. Morphology of Ooctonus vulgatus Haliday, 1833. A. A Antenna. B. $q$ Antenna. C.

564 habitus. D. Head front view. E. Mesosoma lateral view. F. §̋ Propodeum. G. Mesosoma dorsal 565 view. All scales $=100 \mu \mathrm{m}$ except habitus. Photo credit: Jean-Yves Rasplus INRA.

567 Figure 3. Geographical distribution of $\boldsymbol{O}$. vulgatus.

568 A. Distribution of 0 . vulgatus occurrences collected from the literature. B Consensus model of 569 climate suitability estimated by Maxent: median of model outputs. C Consensus model of climate 570 suitability estimated by Maxent: proportion of models predicting $O$. vulgatus presence in Europe. 


\section{Figure 1}

Parasitism rate of Philaenus spumarius eggs in the four sites sampled in Corsica.

Size of the pie chart is proportional to the total number of eggs that hatched from each locality (n). Slices indicate the relative proportion of $O$. vulgatus (dark grey) and nymphs of $P$. spumarius (light grey) that emerged from the pool of eggs. GPS coordinates of sampling localities: $42.984205^{\circ} \mathrm{N}, 9.395287^{\circ} \mathrm{E}$ (Ersa); $42.338849^{\circ} \mathrm{N}, 9.180636^{\circ} \mathrm{E}$ (Tralonca);

$42.274756^{\circ} \mathrm{N}, 9.487185^{\circ} \mathrm{E}$ (Canale-di-Verde); $41.931726^{\circ} \mathrm{N}, 9.343731^{\circ} \mathrm{E}$ (Ventiseri). The map was built with the R package maps, using data from UNESCO (1987) through UNEP/GRIDGeneva. 


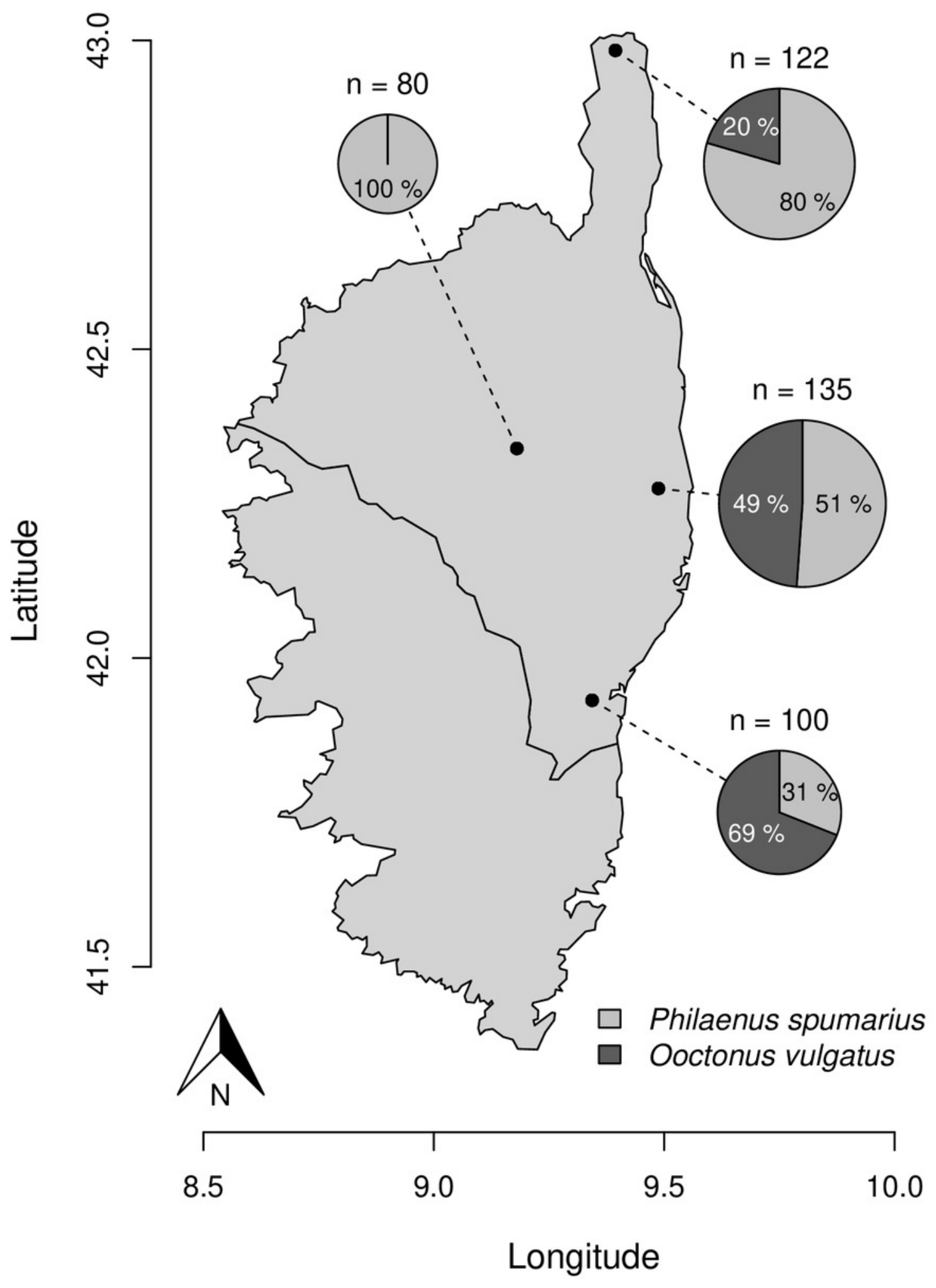


Figure 2

Morphology of Ooctonus vulgatus Haliday, 1833.

A. ơ Antenna. B. @ Antenna. C. habitus. D. Head front view. E. Mesosoma lateral view. F. ơ Propodeum. G. Mesosoma dorsal view. All scales $=100 \mu \mathrm{m}$ except habitus. Photo credit: Jean-Yves Rasplus INRA. 


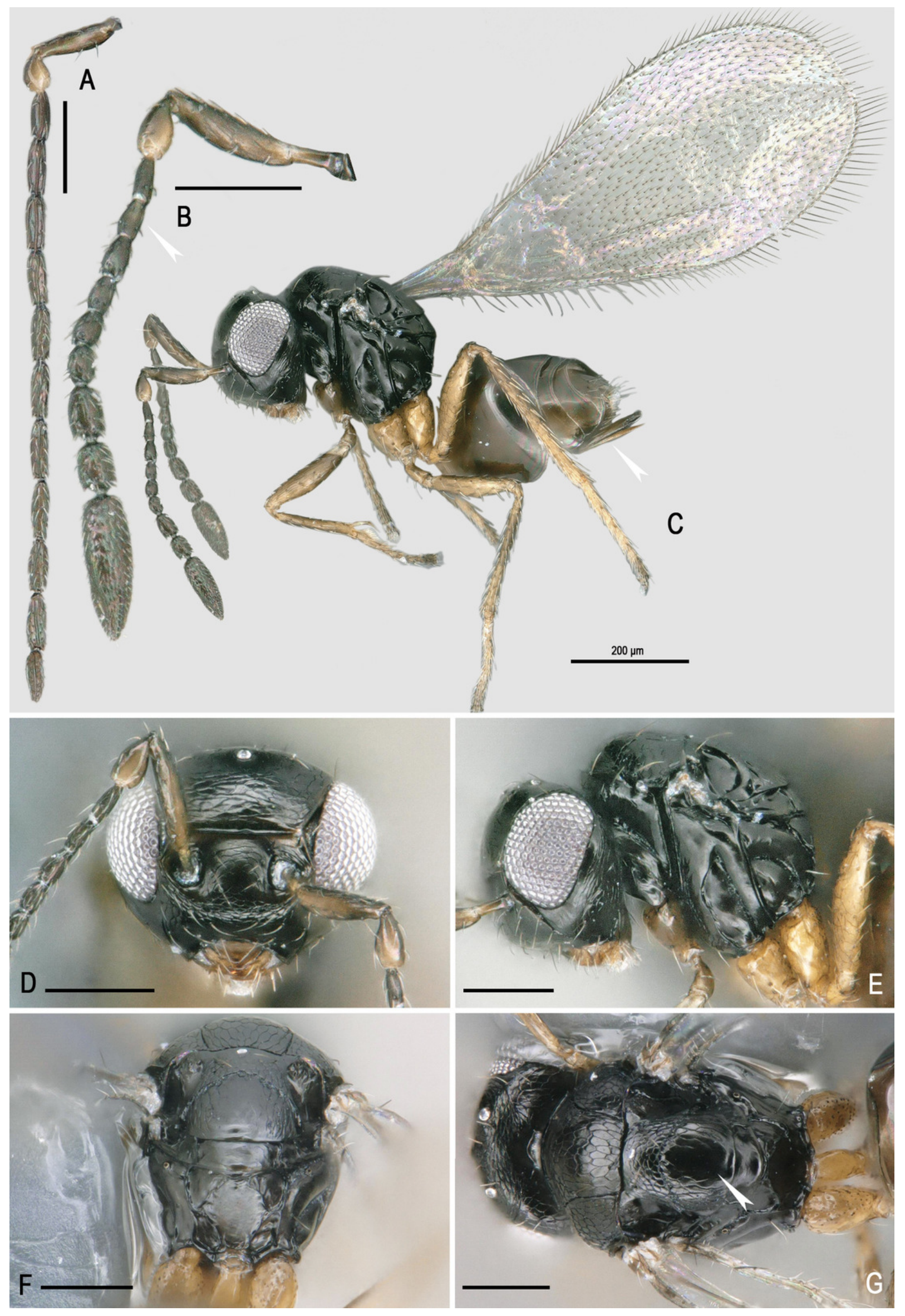


Figure 3

Geographical distribution of $O$. vulgatus.

A. Distribution of $O$. vulgatus occurrences collected from the literature. B Consensus model of climate suitability estimated by Maxent: median of model outputs. C. Consensus model of climate suitability estimated by Maxent: proportion of models predicting $O$. vulgatus presence in Europe. 
A

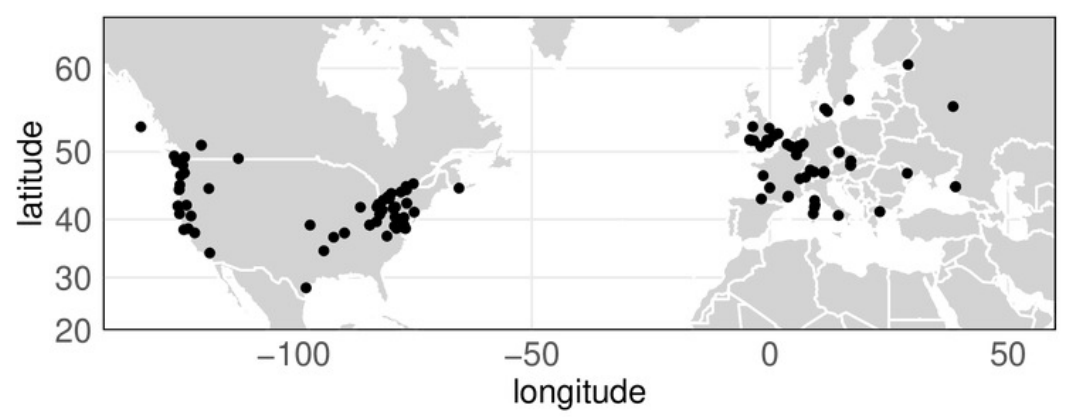

B

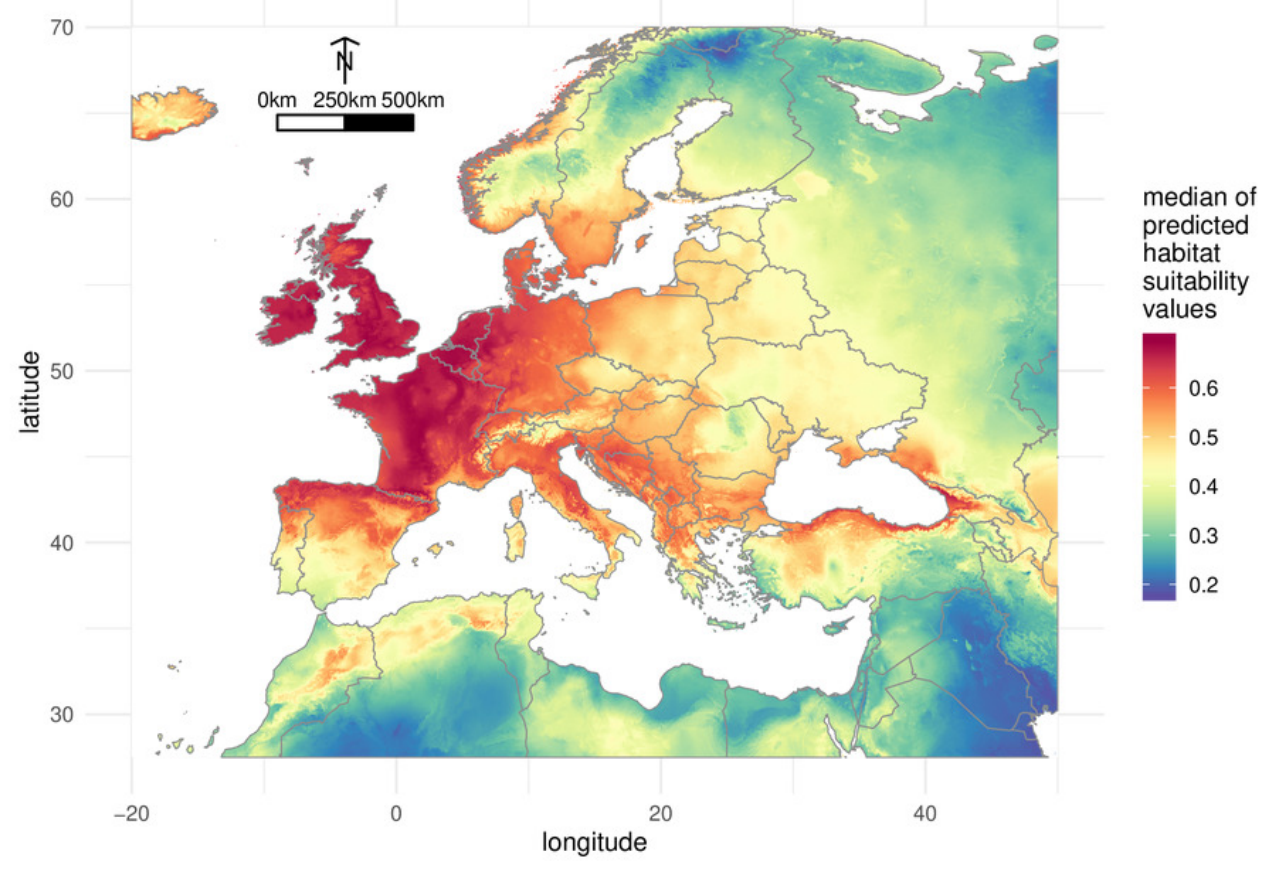

C

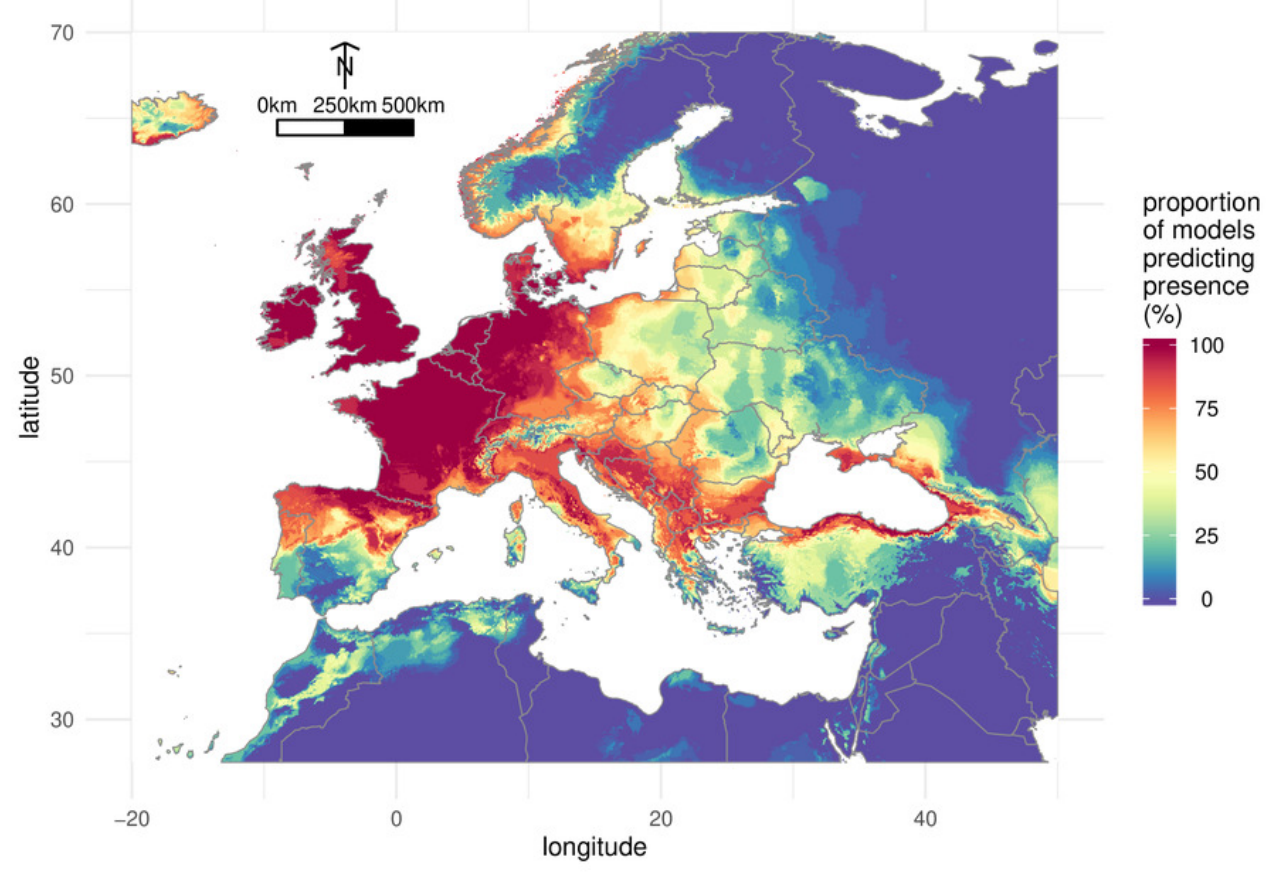

